Preface

\title{
Digging deeper: A tribute to Wolfgang Kaim at the occasion of his 60th birthday
}

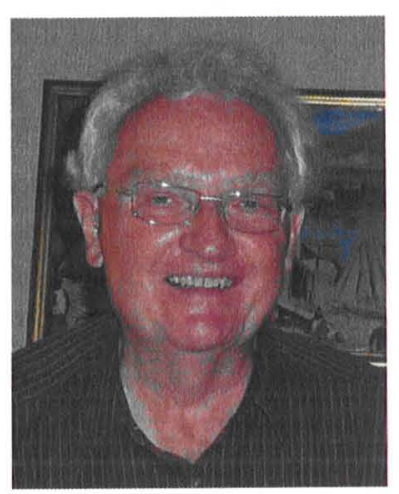

This volume is dedicated to Wolfgang Kaim on the occasion of his 60th birthday. It brings together dedicated contributions of Prof. Kaim's former students, present and past collaborators, friends and colleagues from around the world. These are people who sincerely appreciate the continuous contributions of Prof. Kaim to the synthesis and electronic structure elucidation of inorganic, organic and organometallic systems with relevance to electron transfer, catalysis and bioinorganic chemistry.

"Who only understands (in)organic chemistry does not even understand this one right". This bold statement based on a aphorism of Lichtenberg was the motto of Wolfgang Kaim's 1983 review on "The versatile chemistry of 1,4-diazines" covering organic, inorganic and biochemical aspects. That very statement made him not only friends within the community, but is a paradigm to his entire scientific oeuvre. It says much about his attitude towards chemistry in general and the topics he chose to work on. It is the intricacies of redox-active metals and ligands, their bonding and their physical properties that can be used to probe it, that caught his interest. This highly generalistic, integrated view on chemistry is well founded in his education and background and enabled him well to converse with scientists from neighboring disciplines like physics and biology in a highly productive manner.

Wolfgang Kaim was born and raised in Bad Vilbel, a town at the interface between the cosmopolitan city of Frankfurt am Main, Germany's thriving banking capital dubbed as "Mainhattan", and the more rural part of the German state of Hessen. After briefly considering careers in music (he was an avid player of the electric guitar with Jimi Hendrix as his idol and some would catch him listening to his music as he was taking a break) or mathematics he was converted to physical chemistry by his science teacher, a former student of Friedrich Hund. At the advice of Hermann
Hartmann at Frankfurt University he took a few parallel semesters of Theoretical Physics with Walter Greiner before falling under the spell of Hans Bock and his team at the Institute of Inorganic Chemistry. Still, he left Frankfurt for three semesters to carry out a 'Diplomarbeit' in physical-organic chemistry with Ewald Daltrozzo where he got a thorough introduction into optical spectroscopy. Besides his scientific interest into this matter, it was the special atmosphere of the University of Konstanz, a young University with flat hierarchies and strong student involvement in University life that attracted him. Returning to Frankfurt he started a Ph.D. project on main group radicals in Hans Bock's group, collaborating with Heinrich Nöth, Nils Wiberg, Hideki Sakurai, Mitsuo Kira and Bob West. After graduation at the age of 26(!), the sense of a deficit of 'real inorganic chemistry' in Hans Bock's group led Wolfgang Kaim to push for a post-doctoral stint (1978-1979) with F.A. Cotton at Texas A\&M University with a stipend from the Foundation of the German Chemical Industry. Fifteen publications and 11 months later Wolfgang Kaim had to decide on whether to pursue an academic career or go to industry, as he had originally planned. Opting for the academic path he decided to return to Frankfurt, again to the group of the charismatic Hans Bock, to conduct research on the electron transfer reactivity of main group organometallic compounds with organic heterocycles as substituents or ligands. This research laid the foundations of his interest in complexes of particularly the electron-accepting nitrogen-containing organic heterocycles (bipyridines, tetrazines) and their open-chain counterparts such as diazabutadienes or azobipyridines or of the TCNX-type ligands that continues until today. After finishing his Habilitation in 1982, he received the prestigious Winnacker Fellowship. This allowed him to broaden his research and teaching program, involving transition metal compounds, new stable organic radicals and their complexes and bioinorganic chemistry, all supported by a dedicated group of young students. In 1987 , when the first Ph.D. graduates completed their exams, Wolfgang Kaim agreed to take up a chaired position at the University of Stuttgart. It says much about his personal aura and the appeal of his research that several students, who just had graduated from the Hans Bock group, decided to join him and accompany him to Stuttgart. The Frankfurt team of the "first hours" thus formed the core of his rapidly expanding Stuttgart group. With a keen eye for future developments he set up a new specialist course on the then-young field of Bioinorganic Chemistry. In doing so, he noticed a lack of a suitable textbook that would pay adequate attention to the functional role of the inorganic components within the active sites of metal-containing enzymes. This made him and his coworker Brigitte Schwederski devise and write a textbook on their own. The book, which was first released in 1991 in German language, became an immediate success, winning its authors the "New Textbook Award" of the German Chemical Society. An English transla- 
tion followed in 1994. It ensued that this textbook became not only an interdisciplinary but also worldwide success. Meanwhile, the growth of Wolfgang Kaim's group resulted in the branching and a quantitative expansion of research interests. Soon, the group's work covered the areas of radical stabilization by metal coordination ('non-innocent ligands'), coenzyme models, the extension of mixed-valence chemistry, electron transfer effects on $\mathrm{M}-\mathrm{C}$ and $\mathrm{M}-\mathrm{H}$ bonds, the crystallization of new organic radicals, the electron transfer properties of boron compounds, spectroelectrochemistry in the IR, UV/Vis/near-infrared regions as spectroscopic probes for electron transfer sites and the consequences of electron transfer on structure and bonding, and (high-field) EPR spectroscopy as a less common but highly useful methodology. Crucial to the group's development was the availability of advanced spectroscopic and electrochemical facilities, much of them financed through grant money. All electrochemical and spectroscopic experiments could thus be conducted in the group's own laboratories, thus enabling the highly integrated approach that became its hallmark. This attracted many Ph.D. students, 55 of whom have already graduated from Wolfgang Kaim, post-doctoral students, visiting scientists, and young scientists that found the spirit and possibilities offered by his group an ideal seeding ground for their own growth. The list of funding institutions supporting them covers the entire spectrum of national and international granting agencies including several Humboldt fellowships. Many visiting scientists came as awardees at advanced stages of their careers. Wolfgang Kaim became a scientific partner who was heavily sought for, and his group became constantly involved in collaborative projects and extensive international cooperations. His many national and international partners have well left their traces in the presently more than 550 publications authored or co-authored by Wolfgang Kaim. Particularly strong ties were made to various groups in Argentina, Chile, India and the US, and many of his colleagues will readily agree that they profited a lot from them. But it was not only them who profited: Many of Wolfgang Kaim's students enjoyed the opportunity to broaden their personal horizons by visiting his collaborators' laboratories and working on joint projects.

Wolfgang Kaim ever was an avid and well-received contributor to many scientific meetings all over the globe and a sought-for visiting scientist, and he remains so until today. Besides giving the group strong international visibility, the personal encounters made during conferences and meetings helped to intensify established links with leading scientists from around the world and to generate new ones. This always let his group feel the very pulse of science and gave it a truly international spirit of openness and willingness to share and learn. This spirit is exemplified by the many great scientists who, through collaborations or invitation, found their way to Stuttgart to present and discuss their work. For us who witnessed many such incidents over the years, the depth of insight shown by Wolfgang Kaim and his ability to pose the right ques- tions and to produce new ideas was always astounding and inspiring. It should be added here that his questioning and discussion was always done with the intention to reach a deeper level of understanding or to help but never with the intention to vulnerate or humiliate.

Our own long association with Wolfgang Kaim has helped us in appreciating not only his scientific qualities but also his human nature. In a fast changing scientific world where salesmanship is sometimes more important than scientific content, Wolfgang Kaim has always let his science do the talking for him. One often hears of the so called 'British Understatement'. If there is something called a scientific 'German Understatement' then Wolfgang Kaim certainly epitomizes that. This is a character of his which often his colleagues find extraordinary and difficult to believe. A famous colleague once commented "When I meet Prof. Kaim at conferences, he comes across as such an agreeable person that I often wonder how he manages to run such a large and successful scientific group." This, in essence, sums up his human nature. Those who came to visit or work with him always found him to be a most generous host. He always kept track of those who once were attached to him, bringing them together on several occasions. The celebration of his 60th birthday will be no exception.

Wolfgang Kaim's scientific career has been really diverse and he has contributed to a large variety of different chemical problems as discussed above. His foresight in research is exemplified by his early interest in 'non-innocent' ligands, and their importance to chemistry and nature. Wolfgang Kaim already wrote a review article on that topic in 1987 (see e.g. 'Transition Metal Chemistry of Anion Radicals', Coord. Chem. Rev. 1987, 76, 187), heralding the maturing of this area to a vibrant field of research. The number of dedicated articles in this special issue and the number of countries which the authors represent are a token of how well his achievements and Wolfgang Kaim himself are appreciated throughout the community.

As Wolfgang Kaim celebrates his 60th birthday, we wish him all the best for the years to come, good health and many more exciting findings. We would also like to take this opportunity to thank him for helping us in shaping our own scientific careers and teaching us that, after all, it is simple, sound science that counts.

Biprajit Sarkar Institut für Anorganische Chemie, Universität Stuttgart, Pfaffenwaldring 55, D-70550 Stuttgart, Germany E-mail address: sarkar@iac.uni-stuttgart.de

Rainer F. Winter Fachbereich Chemie, Universität Konstanz, Universitätsstraße 10,

D-78457 Konstanz, Germany E-mail address: rainer.winter@uni-konstanz.de 